\title{
Poverty-centred rural road funds sharing in sub-Saharan Africa
}

1 Andrew Grace Naimanye PhD, MSc (Eng), BEng, CEng, MICE, MCIHT

Road Fund Manager, Uganda Road Fund, Kampala, Uganda (corresponding author: anaimanye@hotmail.com)
2 Tony Whiteing $\mathrm{PhD}, \mathrm{MA}, \mathrm{BSC}$ (Econ), MCILT Senior Lecturer, Institute for Transport Studies, University of Leeds, Leeds, UK
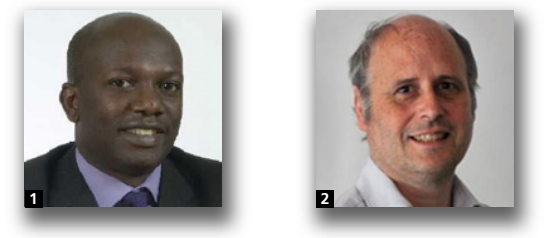

Poverty-centred allocation of funds for rural roads and their systematic prioritisation are important to enhance sustainability, provide equality of transport opportunities and mitigate poverty. The aim of this work was to investigate and develop new approaches with specific emphasis on sub-Saharan Africa, given that the existing decision systems do not appropriately consider social impacts and poverty. An understanding of rural road funds allocation and road scheme prioritisation to alleviate poverty is important as road transport is by far the most predominant form of transport in Africa. This study developed new allocation and prioritisation processes for rural roads based on expert opinion surveys and empirical evidence, which were then applied to analyse allocation and road scheme selection processes used in Uganda and Ghana. The study found that the multi-dimensional poverty index is the most highly prioritised factor in rural road scheme selection and, for regional rural road funds sharing, poverty is equally weighted with the rural accessibility index. A goal programming model, based on expert opinion weightings, is recommended for poverty alleviation.

\section{Notation}

$\mathrm{AL}_{\text {in }} \quad$ specified/optimal attainment level for $i$ th project/road

$C_{i n} \quad$ per unit consequence contribution of the $i$ th project/road

\section{$\mathrm{CF}_{z} \quad$ climatic factor for area $z$}

$d_{i} \quad$ amount by which the solution falls short of the $i$ th goal

$\mathrm{FA}_{r} \quad$ funding availability/project cost factor or cash flow constraint for the $r$ th road

$\mathrm{IE}_{r} \quad$ implementation efficiency factor (absorption constraint) for the $r$ th road

$K_{41} \quad$ population impact factor (default value is $0 \cdot 45$ )

$K_{42}$ length impact factor (default value is 0.35 )

$K_{43} \quad$ equity factor (default value is $0 \cdot 20$ )

$L_{s z} \quad$ total length of road surface type $s$ under designated authority $z$

$M_{s j} \quad$ allocation to road network jurisdiction $j$ ( $j=$ community access roads) and road surface $s$

$M_{s z} \quad$ allocation to designated authority $z$ for road surface type $s$

$n \quad$ number of goals (objectives)

$P_{i} \quad$ priority factor of the $i$ th objective

$\mathrm{POP}_{z} \quad$ population of area $z$

$\mathrm{UF}_{z} \quad$ unit cost factor for area $z$ (default value is $1 \cdot 0$ )
$w_{i}$ weight applied to the $i$ th goal (the unit penalty rate for not satisfying goal $i$ )
$X_{i} \quad$ support level of the $i$ th project/road

\section{Introduction}

Road transport is by far the most predominant form of transport for both passengers and freight in rural sub-Saharan Africa (SSA) and this situation is unlikely to change in the foreseeable future as alternative transport provisions are very limited. Furthermore, rural transport is expensive and is likely to remain so for a long time (Bullman, 1982), which will continue to affect transport opportunities, social impacts and poverty levels. Nevertheless, according to Hine et al. (1983), the improvement or reconstruction of a rural road has limited impact on agricultural prices but the improvement of a footpath to a road providing vehicular access has a beneficial effect that is of the order of a hundred times that of improving an existing rural road - this is measured in terms of adjustments in farm gate prices as farmers and traders shift from head-loading to motorised vehicles to buy and sell produce. Consequently, the upgrading of footpaths and community access roads is likely to alleviate poverty, particularly in rural remote areas in developing 
countries. Similarly, inappropriate rural transport is a major factor contributing to the poverty of the rural population in most developing countries (Hine, 2014). There is therefore a need for new poverty-centred approaches.

The roads in SSA during colonial times were built primarily for the exploitation of mineral and agricultural resources. The driving factor in the location of roads was to link mines, plantations and other sites for the exploitation and transportation of natural resources to ports, rather than to provide general connectivity within the region or at country level (Gwilliam, 2011; Porter, 2002). This created spatial polarisation and poor territorial cohesion and it can therefore be argued that rural road transport investment and road funds allocation in SSA has not been driven by poverty or social impact from the outset.

Road infrastructure planning in SSA and most developing countries is dominated by political connotations and focuses disproportionately on the national road network at the expense of the district and feeder roads that benefit rural inhabitants. In most countries in SSA, expert opinion is that poor planning, inappropriate and uncoordinated resource allocation combined with inadequate corporate governance in road sector institutions has to some extent undermined poverty alleviation efforts. Moreover, prolonged inequity is likely to exacerbate poverty in society and can be a trigger for conflict. Transport can affect equality by creating fair societies or it can also cause disparities between different or within the same regions (Beyazit, 2011). Similarly, transport plays a pivotal role in assuring social justice in societies by distributing social and economic benefits.

The central theme of this study was to use goal programming (GP) as a method to establish allocation and road prioritisation processes using expert opinion surveys to determine the weights (rankings) of key factors. GP is a pragmatic and flexible method that is capable of analysing complex decision problems where several objectives and many variables and constraints are involved.

The research design used case studies from typical developing countries in SSA - Uganda and Ghana - and involved a combination of both quantitative and qualitative methods. Furthermore, two web-based expert surveys were undertaken to seek opinions on rural road scheme prioritisation and road funds allocation in SSA (Naimanye, 2015).

The rationale and motivation of this work is discussed in Section 2. Section 3 provides a definition of poverty and its effects. Section 4 presents the research methodology, Section 5 analyses expert opinion on regional rural road funds allocation, Section 6 proposes the GP models and Section 7 analyses case studies of Uganda and Ghana. Section 8 provides research limitations and, finally, conclusions and recommendations are presented in Section 9.

\section{Rationale and motivation}

As already mentioned, in SSA countries, there is more emphasis on funds allocation towards national roads to the detriment of district and community access roads (rural roads) and these have 'been neglected by most governments in developing countries' (Robinson and Stiedl, 2003: p. 70). However, it can be argued that rural roads serve 'the majority of the population’ (Dalvi, 1987: p. 160). Similarly, when compared with national roads, rural roads provide salient links in the social capital network. The above-cited scholars support the notion of prioritising rural roads with the goal of poverty alleviation, considering that SSA is believed to have the worst accessibility of any populated region in the world. For example, fewer than $40 \%$ of rural Africans live within $2 \mathrm{~km}$ of all-season roads. The majority of rural Africans therefore have long distances to travel in order to access services, using time that could have been used for more productive activities. Furthermore, physical isolation is a strong contributor to poverty and accentuates vulnerability. Consequently, rural road investment is likely to reduce poverty associated with spatial isolation, hence the need for new poverty-centred approaches to enhance sustainability.

It is widely acknowledged that rural road scheme prioritisation in SSA and most developing countries is not very systematic and is often subject to political manipulation due to a lack of clear and all-encompassing guidance that takes account of the views of all key stakeholders and experts; moreover, in most cases, allocations are not poverty-centred. Raballand et al. (2010: p. 47) point out that 'road-building funds are usually not allocated on the basis of any systematic prioritisation arrived at through a modeling process... [and] roads are used as political tools'. This results in a lack of equality of transport opportunities and further accentuates poverty.

Rural road infrastructure can reduce inequality and inequity if it improves accessibility for the poor. In SSA, it is believed that the lack of good roads has played a big role in exacerbating poverty and has been a hindrance to commerce and trade. Furthermore, road sector reforms have affected rural roads much less, despite agriculture being an engine for poverty alleviation and the fact that agriculture is the most important economic activity in rural SSA.

Road planning undertaken using traditional criteria considers road conditions or the required intervention level as the main criteria in order to establish a road maintenance plan; only in some cases is the socio-economic importance of the road influence area and historical maintenance record taken into account (PIARC, 2013). Moreover, evaluation of low-volume roads in developing countries is often challenging to undertake using standard cost-benefit analysis (CBA) as road user savings are negligible (Leinbach and Cromley, 1983). However, it is widely acknowledged that poverty effects and social impacts are not considered adequately in CBA, which is the 
traditional method of road scheme investment appraisal in SSA. While recognising the historically established advantages of the conventional CBA approach, it does not adequately take account of poverty considerations, which fall into the category of indirect or wider effects of transport infrastructure projects and are difficult to evaluate. Moreover, the World Bank suggests that the use of pure economic indicators as decision tools can potentially lead to a vicious circle being created where investments actually widen the income gap (World Bank, 2005). Therefore, it is important that new poverty-centred systems are developed to reduce the burdens of the rural poor in SSA and thus enhance sustainability.

\section{Definition of poverty and its effects}

There is some evidence to suggest that poverty to some degree is negatively correlated with equity (most economically equitable societies have relatively lower levels of poverty). Therefore, lack of equity is likely to exacerbate poverty (as equity decreases poverty increases and vice versa). Poverty is usually measured by assessing income or expenditure based on an established poverty line below which an individual or household is classified as poor, and the World Bank uses a poverty line of income of US $\$ 1.90$ per day below which someone is classified as poor. However, this is a one-dimensional concept. An alternative way is to take account of the multi-dimensionality of poverty and specify the various ways an individual experiences poverty. A person experiences poverty when s/he falls below several poverty lines. A multi-dimensional poverty index (MPI) that takes account of health, education and standard of living is most appropriate as the factors are closely linked to the Millennium Development Goals (Alkire and Santos, 2010). Nonetheless, the MPI could be further improved by embedding transport and accessibility as some of the indicators to be assessed within the three key MPI measures.

In 2000, the World Bank (2000) described poverty in terms of the following four dimensions.

- Opportunity - a lack of access to labour markets, employment opportunities and productive resources. Transport contributes to economic growth by mobilising human and physical resources.

- Capability - a lack of access to public services such as education and health, and hence inability to build human capabilities. Transport can play a big part in improving this attribute of poverty by providing access to education and health facilities; this constitutes access to opportunities and means to improve human capital.

- Security - vulnerability to economic risks and to civil and domestic violence. Transport should contribute to greater security by removing any sense of vulnerability through isolation.

- Empowerment - being without voice and without power at the household, community and national level. Transport is a mechanism for supporting effective participation.
Therefore, changes in transport conditions will have a series of impacts and benefits upon these four dimensions of poverty.

The rural transport system is often closely integrated into the agricultural marketing system and its improvement will almost always lead to poverty reduction and improvement of social impacts. Hine (2014: p. 15) observed that economic theory indicates that road investment is most likely to stimulate rural development if

- it induces a relatively large change in transport costs; a major improvement of a long road will have a greater chance of impact compared with a minor improvement of a short road

- there are unused resources of land and labour to exploit and

- there are dynamic urban markets to absorb new production.

Several studies have revealed that the availability or unavailability of transport affects poverty levels and shapes people's life opportunities (Lucas, 2006; Martens, 2012). Adequate transport provision in SSA is necessary for economic empowerment by providing access to education and employment in addition to health facilities, which are all important for poverty alleviation.

In 2004, the UK Department for International Development (DfID, 2004) prepared a guide for pro-poor transport appraisal that identifies the nature of social benefits and how they can be measured using indicators. The salient aspect of the guidance is the participatory approach at all levels in the determination of social impacts by involving local communities, transport users and decision makers. The aforesaid notwithstanding, detailed and protracted consultations with local communities are likely to be expensive, especially for sparsely populated and remote areas of rural SSA. Moreover, social benefits (impacts) tend to be multi-dimensional and not easily quantifiable and affect individuals at varying levels depending on their needs and circumstances, thus requiring detailed consultations.

\section{Research methodology}

A web-based panel of experts with experience in road funds allocation and road scheme prioritisation in SSA was set up as part of this research, and two rounds of surveys were undertaken; the first stage involved 44 panellists and the second stage comprised 29 panellists (Naimanye, 2015). The second stage survey was more detailed and was based on the findings of the first survey. The experts were mainly managerial staff of road funds and road authorities in SSA; they were located or had road funds allocation/road scheme prioritisation experience in various countries including Uganda, Ghana, Zambia, Kenya, Tanzania, Namibia, Zimbabwe, Malawi, South Africa, Canada, USA, UK, Mozambique, France, Netherlands, New Zealand and Ethiopia. 
Experts were requested to provide a weighting of the most important factors in road scheme prioritisation for both capital investment projects and maintenance schemes for the various network classes of national roads, rural roads and urban roads. The derived weightings (rankings) analysed in the following section were then applied to assess rural road funds allocation in Uganda and Ghana (Section 6).

\section{Results of expert opinion on road funds allocation and road scheme prioritisation}

The experts agreed that prioritisation of national roads should be purely on economic efficiency criteria. However, when considering rural roads, multi-criteria analysis should be used and social equity (impacts of personal, economic or social characteristics) and multi-dimensional poverty should be highly prioritised. Furthermore, the experts concurred that the community should be involved at all stages in rural road scheme prioritisation.

Table 1 shows the panel's weights (average) for the key factors considered important for road scheme prioritisation for new road projects (capital investment).

Analysis of the results in Table 1 shows that, for prioritisation of new rural road projects, multi-dimensional poverty should be weighted at $36 \%$ and economic efficiency at $32 \%$, while regional connectivity and political consideration should each be weighted at $16 \%$. Therefore, the MPI is the most important factor in the prioritisation of new rural road projects.

The expert weightings (average) for the most important factors to consider when prioritising road maintenance schemes are analysed in Table 2. Analysis of the results in Table 2 shows that, for prioritisation of rural road maintenance projects, economic efficiency and multi-dimensional poverty should each be weighted at $35 \%$, while regional connectivity should be weighted at $17 \%$ and political consideration at $13 \%$. One interesting finding when comparing Tables 1 and 2 is that the experts' weightings for prioritisation of new road projects and maintenance are not very different. Furthermore, for both

\begin{tabular}{lccc} 
Critical factor & \multicolumn{3}{c}{ Weighting } \\
\cline { 2 - 4 } & $\begin{array}{c}\text { National } \\
\text { roads }\end{array}$ & $\begin{array}{c}\text { Rural } \\
\text { roads }\end{array}$ & $\begin{array}{c}\text { Urban } \\
\text { roads }\end{array}$ \\
\hline Economic efficiency & 0.54 & 0.32 & 0.50 \\
MPI & 0.14 & 0.36 & 0.27 \\
Regional connectivity & 0.22 & 0.16 & 0.11 \\
Political consideration & 0.10 & 0.16 & 0.12
\end{tabular}

Table 1. Expert weightings of key factors in prioritisation of new road projects

\begin{tabular}{lccc}
\hline Critical factor & \multicolumn{3}{c}{ Weighting } \\
\cline { 2 - 4 } & $\begin{array}{c}\text { National } \\
\text { roads }\end{array}$ & $\begin{array}{c}\text { Rural } \\
\text { roads }\end{array}$ & $\begin{array}{c}\text { Urban } \\
\text { roads }\end{array}$ \\
\hline Economic efficiency & 0.54 & 0.35 & 0.49 \\
MPI & 0.15 & 0.35 & 0.28 \\
Regional connectivity & 0.22 & 0.17 & 0.11 \\
Political consideration & 0.10 & 0.13 & 0.12
\end{tabular}

Table 2. Expert weightings of key factors in prioritisation of road maintenance schemes

\begin{tabular}{lc} 
Factor & Weighting \\
\hline Needs basis (road condition and length) & $0 \cdot 23$ \\
Agricultural productivity, extraction of natural & $0 \cdot 22$ \\
$\quad$ resources and tourism & \\
Population density & $0 \cdot 17$ \\
MPI & $0 \cdot 14$ \\
Rural accessibility index & $0 \cdot 14$ \\
Regional connectivity & $0 \cdot 10$
\end{tabular}

Table 3. Expert weightings of key factors for regional allocations

capital investment and road maintenance of rural road projects, the MPI is the most highly prioritised factor.

For rural road funds allocations on a regional basis, the experts believed that needs basis and economic productivity of a region play an important role in allocations. The suggested weightings by the panel as regards regional allocations are indicated in Table 3.

From Table 3, it can be seen that needs assessment is most highly weighted; however, at the micro-level (local regions, villages, sub-counties), network metrics are not accurate and in most cases unavailable. It should be noted that the MPI and the rural accessibility index are equally weighted in regional allocations. The weightings as determined above were used when developing the GP models, both weighted and lexicographic (based on sequentially satisfying priorities).

\section{Goal programming}

It is argued in this paper that rural road funds allocation and scheme prioritisation in SSA ought to be undertaken by GP rather than the use of 'data hungry' complex decisionsupport tools. Taplin et al. (1995) posit that, for each project, a score is obtained from decision makers (experts) or other respondents for each criterion and these scores are standardised into some numerical range and the merit of each project is measured by the sum of the priority weighted scores. 
Here, GP is proposed to be used as follows when prioritising rural road schemes.

- Propose the priority level for each goal/objective.

- Set the weight (score) on each goal. If a priority level has more than one goal, for each goal $i$ decide the weight $w_{i}$ to be placed on the deviation(s) $d_{i}^{+}$and/or $d_{i}^{-}$from the goal.

- Set up a lexicographic GP model and consider new objectives (minimise deviations), subject to all functional and goal constraints.

- Solve the linear program.

Weightings or scores are determined based on expert opinion. The weights may be in terms of scores or an arbitrary monetary value. The approach proposed in this paper comprises two stages, namely strategic level prioritisation (planning and programming level) using weighted GP followed by detailed scheme selection at implementation level using lexicographic GP.

A scheme may score highly at strategic level but poorly at implementation planning level and vice versa. Therefore, the decision maker needs to be cognisant of both scores prior to agreeing a preferred/optimal and poverty-centred solution (Naimanye, 2015). The aforesaid may be considered as boundaries in the Pareto efficiency constraint.

Table 4 shows suggested analysis at strategic planning and programming level based on the experts' suggested factors for rural SSA.

In the first option during prioritisation at strategic level, the principle is to limit the weighted sum of the penalties for deviating from the goals specified in a series of constraints such that the result is a compromise between various competing criteria as illustrated in the formulation below

$$
\text { Minimise } \sum_{i=1}^{n} w_{i} P_{i} d_{i}
$$

Subject to $\sum_{i=1}^{r} C_{i n} X_{i}+d_{i}+\mathrm{IE}_{r}+\mathrm{FA}_{r} \geq \mathrm{AL}_{\text {in }}$

$$
d_{i} X_{i} \geq 0
$$

An alternative approach may be to maximise the weightings and priority factor rather than minimising, such that the schemes are ranked based on the highest scores. Naimanye (2015) provides a worked example of using GP in road scheme prioritisation in Uganda. Having identified the road schemes at strategic level through a weighting GP model, the second option for the detailed selection of road schemes at implementation level takes the form of a lexicographic GP model. The sequential priority levels were set based on the survey results (Tables 1 and 2). Table 5 analyses typical prioritisation of rural roads in SSA using a lexicographic GP model at four priority levels.

\section{Case studies}

\subsection{Critique of Uganda's rural road funds allocation formulae}

Equation 1 shows the community access roads allocation formula previously used by the Uganda Road Fund when allocating funds to sub-counties (villages) (URF, 2014). The allocation formula does not take account of poverty or social impacts at all. Furthermore, there is no scientific justification for the weighting of population at $0 \cdot 85$ and surface area at $0 \cdot 15$, and the weightings are not based on expert opinion or a needs basis. The formula favours allocations to highly populated areas, which in some cases are not the most heavily deprived.

1. $A=P+S$

where $A$ is the allocation to sub-county $X, P$ is the population allocation $\left(=85 \%\right.$ of $\left.Z\left(P x / \sum P\right)\right), S$ is the surface area allocation $\left(=15 \%\right.$ of $\left.Z\left(S x / \sum S\right)\right)$ and $Z$ is the total allocation available.

A new formula for allocation to the various regions at subcounty level for community access roads during the financial year 2014/15 is shown in Equation 2 (URF, 2014).

2.

\begin{tabular}{|c|c|c|c|c|c|c|c|c|}
\hline \multirow[t]{2}{*}{ Road ID ${ }^{a}$} & \multirow[t]{2}{*}{ Cost } & \multirow{2}{*}{$\begin{array}{l}\text { Net present } \\
\text { value }\end{array}$} & \multirow{2}{*}{$\begin{array}{l}\text { Benefit/ } \\
\text { cost ratio }\end{array}$} & \multicolumn{4}{|c|}{ Weighted score } & \multirow{2}{*}{$\begin{array}{l}\text { Total } \\
\text { score }\end{array}$} \\
\hline & & & & $\begin{array}{l}\text { Economic } \\
\text { efficiency }\end{array}$ & $\begin{array}{l}\text { Multi-dimensional } \\
\text { poverty }\end{array}$ & $\begin{array}{l}\text { Political } \\
\text { factor }\end{array}$ & $\begin{array}{l}\text { Region } \\
\text { linkage }\end{array}$ & \\
\hline
\end{tabular}

$$
\begin{aligned}
M_{s z}= & \left(\left\{K_{41}\left[\frac{\mathrm{POP}_{z}}{\sum_{z=1}^{N} \mathrm{POP}_{z}}\right]+K_{42}\left[\frac{L_{s z}}{\sum_{z=1}^{N} L_{s z}}\right]\right\}\right. \\
& \left.\times \mathrm{CF}_{z} \times \mathrm{UF}_{z}+\frac{K_{43}}{N}\right) M_{S j}
\end{aligned}
$$

$R_{1}$ to $R_{n}$

${ }^{\mathrm{a}} R_{1}$ is road 1 and $R_{n}$ is the $n$th road

Table 4. Rural road scheme prioritisation in SSA at strategic level 
Expert-identified priority level 1

Scheme Goal is alleviating multidimensional poverty /enhancing social equity (weighted)

$R_{1}$ to $R_{n}$

Expert-identified priority level 2

Scheme Goal is economic efficiency (weighted)

$R_{1}$ to $R_{n}$

Expert-identified priority level 3

Scheme Goal is regional or international connectivity (weighted)

$R_{1}$ to $R_{n}$

Expert-identified priority level 4

Scheme Goal is political balance (weighted)

$R_{1}$ to $R_{n}$
Measurement and assessment options include health, education, standard of living, travel

Total score

Attainment level

time reductions to amenities, transport

services/accessibility and human development index
Total score

Attainment level Total score Attainment
level distance reduction to neighbouring districts, travel time savings, territorial equity, accessibility index and availability of transport services

Measurement and assessment options could be number of beneficiary constituencies, election pledge, regional balance, ethnicity balance, marginalised population and partisan political catchment
Total score Attainment
level

Table 5. Proposed rural road scheme prioritisation in SSA at

implementation level

The terms in Equation 2 are defined in the notation. The new community access roads allocation formula is data intensive and data collection in SSA is a challenge, especially for rural roads; moreover, the formula does not consider poverty or social impacts. Furthermore, the formula does not provide for consultation with stakeholders, which is a major weakness. Several studies have shown that involvement of the community in planning, management and maintenance ensures that the roads meet the needs of the people and are maintained regularly after construction (DfID, 2003; Symington, 2001).

The World Bank (2010) recommends that road funds allocations to districts in Uganda should take account of agricultural output or potential; however, the existing formulae do not address this important factor which is critical for poverty alleviation. Furthermore, poverty levels in northern Uganda are far higher than the southern part and the allocation formulae do not address the economic divide.

According to Raballand et al. (2010), optimal road maintenance funds allocation by district in Uganda should be a function of agricultural potential, district population, district area and the length and condition of the district road network. The aforesaid is reasonable. However, a better addition and improvement would be explicitly to include factors relevant to multi-dimensional poverty and social impacts.

\subsection{Rural road scheme prioritisation in Uganda}

At lower local government level and before operationalisation of the Uganda Road Fund, rural roads were prioritised using the rehabilitation and maintenance planning system. The system is an updated and expanded data management and planning tool based on the routine maintenance planning system introduced in the districts in 1997. Since operationalisation of the Uganda Road Fund in 2010, rural roads are now prioritised by district road committees, which mainly comprise members of parliament and local leaders. Naimanye (2015) hypothesised that there is no scientific basis in the road scheme selection process and road schemes are prioritised in accordance with the requirements of the local leaders; therefore, selection is used to maintain and strengthen political allegiance or personal benefits. This affects equality of transport opportunities and most probably does not adequately address the need to alleviate poverty.

\subsection{Critique of Ghana's road funds allocation formulae}

Foster and Pushak (2011) observe that Ghana allocates its road fund resources much more evenly, with rural roads 
receiving $30 \%$ and urban roads $25 \%$ of the total and the remainder going to national roads. However, this may not necessarily be poverty-centred or based on needs and expert opinion. In 1997, Mwale (1997) reported that the Ghana Highway Authority (GHA) was allocated 58\%, the Department of Feeder Roads (DFR) received 20\% and the Department of Urban Roads (DUR) 22\%. However, 15 years later (in 2013), the budgetary allocation for rural roads was $26.90 \%$ (DFR) and 26.46\% (DUR) for urban roads (GRF, 2013), which is still not equitable or poverty-centred. The Ghana Road Fund allocations have also been somewhat erratic over time.

Ghana does not have a specific allocation formula to address regional allocations and the main agencies use HDM-4 software in the prioritisation and allocation of resources, which does not adequately take account of poverty or social impacts. Nevertheless, the allocation to the various implementing agencies has a high potential for political interference and there is a general bias of government actions and business growth towards benefiting urban areas more than rural areas (IDL Group, 2014). Furthermore, the allocation strategy does not take account of the north-south economic divide. Table 6 analyses the network parameters, demographics and poverty levels in the Ghana regions during 2006.

Considering the expert weightings developed in Table 3 combined with the parameters for each region as analysed in Table 6, regional funds allocation for feeder roads in Ghana could be undertaken taking account of a uniform factor weighted at $22 \%$ being a proxy for agricultural productivity (which is a function of rural road length), a population factor weighted at $17 \%$, network length/road condition factor at $23 \%$, a land surface area factor at $10 \%$ being a proxy for regional connectivity and an equity factor weighted at $14 \%$ taking account of the MPI of each region and 14\% for road condition being a proxy for accessibility.

\subsection{Road scheme prioritisation in Ghana}

In Ghana, decision-making tools are seldom used effectively to manage, measure, plan, budget for and prioritise the rural road network to enable evidence-based policy discussion (IDL Group, 2014). This view is also supported by Boamah (2010) who argues that there is no investment analysis, which results in inconsistent and distorted road maintenance programmes. However, Boamah (2010) further notes that different tools are used by the implementing agencies in road maintenance budgeting and prioritisations, namely a pavement maintenance management programme by the GHA, a maintenance management system by the DUR and a maintenance performance budgeting system by the DFR.

In terms of investment analysis, Boamah (2010) observes that economic evaluation is undertaken for individual road projects using CBA for GHA and DUR networks, and various appraisal methods are applied for feeder road projects, including (a) an accessibility improvement index, (b) a road area prioritisation model and $(c)$ a road maintenance prioritisation model.

Hine et al. (2000) explain that the Ghana feeder road prioritisation framework aims to maximise economic and social benefits through extensive community participation together with a prioritisation index where social and economic benefits are estimated from predicted changes in accessibility and road roughness. The project was set up in 1999 by the DFR of the Ministry of Roads and Transport in cooperation with the UK Department for International Development and covered nine

\begin{tabular}{|c|c|c|c|c|c|c|}
\hline Region & $\begin{array}{l}\text { Land area: } \\
10^{3} \mathrm{~km}^{2}\end{array}$ & MPI & $\begin{array}{l}\text { Population: } \\
\text { million }\end{array}$ & $\begin{array}{c}\text { Rural } \\
\text { population: \% }\end{array}$ & $\begin{array}{c}\text { Feeder road } \\
\text { length: } 10^{3} \mathrm{~km}\end{array}$ & $\begin{array}{c}\text { Poor and fair } \\
\text { condition roads: \% }\end{array}$ \\
\hline Greater Accra & $3 \cdot 24$ & 0.072 & $4 \cdot 01$ & $9 \cdot 5$ & $1 \cdot 34$ & $72 \cdot 5$ \\
\hline Eastern & $19 \cdot 32$ & $0 \cdot 147$ & $2 \cdot 63$ & $56 \cdot 6$ & 3.99 & $40 \cdot 7$ \\
\hline Volta & $20 \cdot 57$ & $0 \cdot 187$ & $2 \cdot 12$ & $66 \cdot 3$ & $3 \cdot 21$ & $77 \cdot 9$ \\
\hline Ashanti & $24 \cdot 39$ & $0 \cdot 121$ & $4 \cdot 78$ & $39 \cdot 4$ & 5.45 & $66 \cdot 4$ \\
\hline Central & $9 \cdot 83$ & $0 \cdot 155$ & $2 \cdot 20$ & $52 \cdot 9$ & $3 \cdot 10$ & $73 \cdot 8$ \\
\hline Western & $23 \cdot 92$ & $0 \cdot 164$ & $2 \cdot 38$ & $57 \cdot 6$ & $5 \cdot 46$ & $60 \cdot 9$ \\
\hline Brong Ahafo & $39 \cdot 56$ & $0 \cdot 217$ & $2 \cdot 31$ & $55 \cdot 5$ & $7 \cdot 20$ & $58 \cdot 4$ \\
\hline Northern & $70 \cdot 38$ & $0 \cdot 371$ & $2 \cdot 48$ & $69 \cdot 7$ & $6 \cdot 16$ & $66 \cdot 3$ \\
\hline Upper West & $18 \cdot 48$ & $0 \cdot 341$ & $0 \cdot 70$ & $83 \cdot 7$ & $3 \cdot 01$ & $48 \cdot 3$ \\
\hline Upper East & $8 \cdot 84$ & 0.335 & 1.05 & $79 \cdot 0$ & $2 \cdot 08$ & $31 \cdot 5$ \\
\hline Total & $238 \cdot 53$ & & 24.66 & & $41 \cdot 00$ & \\
\hline
\end{tabular}

Table 6. Parameters for measurement of micro-level equity in Ghana's feeder roads programme in 2006 (adapted from GSS (2013)) 
districts in the north-east of the country. The procedure essentially covers the following steps.

- First round of improvements - approximately $50 \%$ of the funds are allocated equally between the nine districts to ensure equitable spread of funds.

- Consultation - a list of candidate roads are drawn up from each district and ranked by local communities prior to technical analysis.

- Technical analysis of candidate roads - the ethos is to assess candidate roads on economic and social grounds, and detailed surveys are undertaken to determine population served, location of important facilities, modal traffic distribution, traffic volumes, road condition in terms of roughness and road improvement costs for both access and full rehabilitation.

- The total benefits are divided by the road improvement costs to determine a prioritisation index.

The Ghana feeder roads prioritisation scheme partly covers social impacts, equity and some aspects of multi-dimensional poverty. However, its major drawbacks are that it is data intensive, costly, lengthy and bureaucratic.

\section{Research limitations}

This study has shown that there are challenges relating to uniform interpretation and analysis of poverty. Poverty assessment is a complex phenomenon due to the various poverty dimensions, different interpretation mechanisms, numerous impacts and data sources, and the wide range of parameters that may be considered. There is no clear definition, in practice or in theory, of what constitutes an exclusive poverty-centred approach for rural road scheme prioritisation or funds allocation.

This research was based on data from Uganda and Ghana and expert opinion was obtained from practitioners with experience mainly in Africa. Prudence is thus required when applying the findings of this paper to other developing countries in SSA and local expert opinion should be sought.

Use of GP models should also be undertaken with caution. Analyses should be undertaken before and after solving the problem to mitigate against modelling pitfalls by use of methods such as normalisation, Pareto efficiency detection and restoration techniques (Tamiz et al., 1998). In the same vein, when using lexicographic models, they should not include an excessive number of priority levels as this creates redundancy problems. However, the limitations are not believed to be detrimental to the conclusions and recommendations of this study.

\section{Conclusions and recommendations}

Analysis of the road funds allocation formulae used in Uganda shows major weaknesses as regards social impacts, poverty and equity. The old formula is simple but there is no scientific justification of the weightings used for population and surface area; in addition, the weightings are not based on expert opinion or needs assessment. The formula favours allocations to highly populated areas, which in some cases are not the most heavily deprived. The new allocation formula is too complex and data intensive, and key stakeholders are not consulted during the allocation process. Furthermore, there is limited scientific analysis in the road scheme selection processes and road scheme prioritisation is politically influenced and not poverty-centred (Naimanye, 2015). Moreover, there is a strong bias towards allocation of funds to national roads although rural roads serve the majority of the populace.

Ghana road fund allocations vary from year to year and are not poverty-centred; moreover, there is a bias towards national roads. Ghana does not have a specific allocation formula to address regional allocations and decision tools are seldom used appropriately. The Ghana feeder roads prioritisation scheme attempted to cover some aspects of multi-dimensional poverty; however, it is data intensive and costly. Allocation systems in both Uganda and Ghana do not consider the historical north-south economic divide that affects poverty and sustainability.

A rural roads authority is important to spearhead povertycentred allocations and rural road scheme prioritisation and to ensure secure long-term funding for rural road development and maintenance. If not in place, then a directorate within the Ministry of Roads (Transport/Works) with appropriate expertise should be in place to champion the case for rural roads. Furthermore, a rural transport strategy/policy with multidimensional poverty highly prioritised should be in place.

In order to address poverty and social impacts adequately, funds should be allocated specifically to clear bottlenecks and not necessarily to rehabilitate roads to a good standard.

For rural road funds allocations on a regional basis, experts believe that a needs basis and economic productivity and potential of a region play an important role in allocations; nevertheless, multi-dimensional poverty should also be highly prioritised. In the same vein, direct labour methods, which offer local employment particularly for women, are important in alleviating poverty. Force account (direct labour) works execution using methods such as 'road gangs' and 'lengthman systems' for routine manual maintenance has a greater trickledown effect in financial benefits for local residents while contracting mainly benefits the contractor unless labour-based contractors are used.

In order to mitigate existing road sector inequities, enhance sustainability and offer equality of transport opportunities, a goal programming model that highly prioritises multidimensional poverty is recommended for SSA rural road scheme selection. Furthermore, rural road funds allocation 
should be based on expert-identified factors with a bias towards poverty alleviation.

\section{REFERENCES}

Alkire S and Santos ME (2010) Acute Multidimensional Poverty: A New Index for Developing Countries. United Nations Development Programme, New York, NY, USA, Human Development Report Office Background Paper no. 2010/11. See http://hdr.undp.org/en/content/acutemultidimensional-poverty (accessed 27/09/2016).

Beyazit E (2011) Evaluating social justice in transport: lessons to be learned from the capability approach. Transport Reviews 31(1): 117-134.

Boamah PA (2010) Development of Models for Optimal Road Maintenance Fund Allocation. A Case of Ghana. $\mathrm{PhD}$ thesis, University of Birmingham, Birmingham, UK.

Bullman N (1982) Foreword. In Highway Investment in Developing Countries. Thomas Telford, London, UK, p. 1.

Dalvi MQ (1987) The mobility problem of the third world. In Moving People in Tomorrow's World. Thomas Telford, London, UK, pp. 151-167.

DfID (Department for International Development) (2003) Community Participation in Road Maintenance; Guidelines for Planners and Engineers, 1st edn. DfID, London, UK, DfID Research Scheme R6476.

DfID (2004) Overseas Road Note No. 22: A Guide to Pro-Poor Transport Appraisal. DfID, London, UK.

Foster V and Pushak N (2011) Ghana's Infrastructure: $A$ Continental Perspective. The World Bank, Washington, DC, USA, Policy Research Working Paper WPS5600.

GRF (Ghana Road Fund) (2013) Ghana Road Fund Presentation to Uganda Road Fund Delegates, 2013. Ghana Road Fund, Accra, Ghana.

GSS (Ghana Statistical Service) (2013) Ghana Statistical Service, 2010 Population and Housing Census Report, Non-monetary poverty in Ghana. GSS, Accra, Ghana. See http://www.statsghana.gov.gh/docfiles/2010phc/ Non-Monetary $\% 20$ Poverty $\% 20$ in $\% 20$ Ghana $\% 20$ (24-10-13).pdf (accessed 14/04/2014).

Gwilliam K (2011) Africa's Transport Infrastructure: Mainstreaming Maintenance and Management. World Bank, Washington, DC, USA. See https://openknowledge. worldbank.org/handle/10986/2275 (accessed 11/11/2013).

Hine J (2014) The Planning and Prioritisation of Rural Transport Infrastructure \& Services. Sub-Saharan Africa Transport Policy Program, World Bank, Washington, DC, USA.

Hine J, Riverson J and Kwakye E (1983) Accessibility, Transport Costs and Food Marketing in the Ashanti Region of Ghana. Transport and Road Research Laboratory, Crowthorne, UK, TRRL Report SR 809.

Hine J, Ellis S and Korboe D (2000) Ghana Feeder Road Prioritisation. World Road Association, Paris, France. See http://www.piarc.org/ressources/documents/actesseminaires0102/c3c20-cambodge02/9127,2.2_TC3-20_ 2002_Hine.pdf (accessed 15/01/2014).
IDL Group (2014) 'More Than Just Roads': Analysing Governance in the Rural Transport Sector. IDL Group, Bristol, UK, Working Paper Number 4. See http://www. theidlgroup.com/documents/report_4.pdf (accessed 03/05/2014).

Leinbach TR and Cromley RG (1983) A goal programming approach to public investment decisions: a case study of rural roads in Indonesia. Social-Economic Planning Sciences 17(1): 1-10.

Lucas K (2006) Providing transport for social inclusion within a framework in the UK. Transportation Research Part A: Policy and Practice 40(10): 801-809.

Martens K (2012) Justice in transport as justice in accessibility: applying Walzer's 'spheres of justice' to the transport sector. Transportation 39(6): 1035-1053.

Mwale SM (1997) Road Sector Reform: A Tale of Two Countries (Part I) Ghana: Serendipity or Foresight? World Bank, Washington, DC, USA, Africa Transport Technical Notes, No. 6, SSATP.

Naimanye AG (2015) Development of Equitable Algorithms for Road Funds Allocation and Road Scheme Prioritization in Developing Countries, A Case Study of Sub-Saharan Africa. $\mathrm{PhD}$ thesis, Institute for Transport Studies, University of Leeds, Leeds, UK. See http://etheses.whiterose.ac.uk/13137/ (accessed 01/07/2016).

PIARC (World Road Association) (2013) Best Practices for the Sustainable Maintenance of Rural Roads in Developing Countries; Technical Committee A.4 Rural Road Systems and Acceptability to Rural Areas. PIARC World Road Association, Paris, France. See http://www.piarc.org (accessed 09/08/2014).

Porter G (2002) Living in a walking world: rural mobility and social equity issues in sub Saharan Africa. World Development Report 30(2): 285-300.

Raballand G, Macchi P and Petracco C (2010) Rural Road Investment Efficiency, Lessons from Burkina Faso, Cameroon and Uganda. World Bank, Washington, DC, USA. See http:/gtkp.com/assets/uploads/20100915-1001311147-WorldBank_RuralRoadInvestmentEfficiency_2010. pdf (accessed 30/03/2014).

Robinson R and StiedI D (2003) Decentralisation in developing countries: a model for road administration. Proceedings of the Institution of Civil Engineers - Transport 156(2): 65-71, http://dx.doi.org/10.1680/tran.2003.156.2.65.

Symington R (2001) Briefing: Community participation in road maintenance. Proceedings of the Institution of Civil Engineers - Municipal Engineer 145(4): 317-319, http://dx.doi.org/10.1680/muen.2001.145.4.317.

Tamiz M, Jones D and Romero C (1998) Goal programming for decision making: an overview of the current state-ofthe-art. European Journal of Operational Research 111(3): 569-581.

Taplin JHE, Qiu M and Zhang Z (1995) Policy-sensitive selection and planning of road investments with a goal program. Transport Policy 2(4): 251-256. 
URF (Uganda Road Fund) (2014) One Year Road Maintenance Plan for 2014. URF, Kampala, Uganda.

World Bank (2000) World Development Report 2000/2001: Attacking Poverty. The World Bank, Washington, DC, USA.
World Bank (2005) Transport Notes: Transport Note TRN-26. The World Bank, Washington, DC, USA.

World Bank (2010) Uganda Public Expenditure Review; Strengthening the Impact of the Roads Budget. The World Bank, Washington, DC, USA, Report No. 55672-UG.

\section{HOW CAN YOU CONTRIBUTE?}

To discuss this paper, please email up to 500 words to the editor at journals@ice.org.uk. Your contribution will be forwarded to the author(s) for a reply and, if considered appropriate by the editorial board, it will be published as discussion in a future issue of the journal.

Proceedings journals rely entirely on contributions from the civil engineering profession (and allied disciplines). Information about how to submit your paper online is available at www.icevirtuallibrary.com/page/authors, where you will also find detailed author guidelines. 